\title{
Rupture of a Renal Hydatid Cyst into the Renal Pelvis
}

Key words: hydatid cyst, renal pelvis, rupture
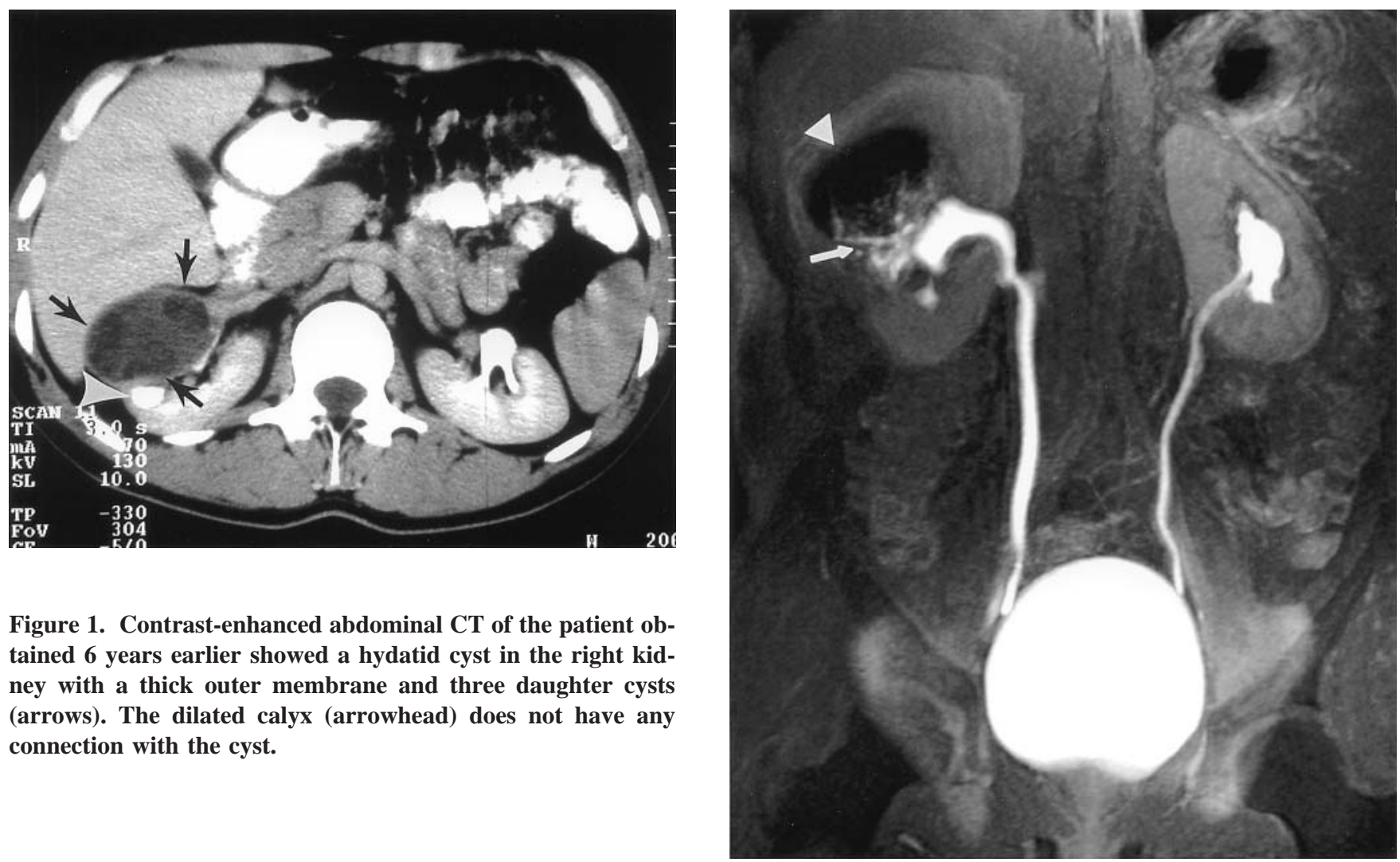

Figure 1. Contrast-enhanced abdominal CT of the patient obtained 6 years earlier showed a hydatid cyst in the right kidney with a thick outer membrane and three daughter cysts (arrows). The dilated calyx (arrowhead) does not have any connection with the cyst.

Figure 2. Gadolinium-enhanced three-dimensional MRurography reveals the hydatid cyst in the right kidney (arrowhead). The contrast filling indicates a connection between the cyst and the urinary collecting system (arrow).

A 43-year-old man was admitted with voiding of a grape-like material. He had been diagnosed to have renal hydatid cyst six years previously by serology and radiology: hemaglutination test was positive at dilutions up to $1 / 2,056$; CT revealed the cyst in the right kidney with thick outer membrane and daughter cysts and also dilated calyx without any connection with the cyst (Fig. 1). He did not agree to surgical treatment. He was given albendazole therapy of $800 \mathrm{mg} /$ day in a cycle of 28 days with an interval of two weeks. After six cycles, a control CT showed the persisting cyst with comparable measurements. Two years previously, he reported the first episode of voiding a grape-like material and histology was consistent with the cuticular membrane of an echinococcal cyst. Five days ago, he voided clear fluid with membranous materials. An MR urography revealed the cyst in which the contrast filling indicated the connection with the urinary collecting system (Fig. 2).

Hydatid disease is a parasitic infestation caused by Echinococcus granulosus. The cysts tend to form mainly in the liver (50 to $70 \%$ ) or lung (20 to $30 \%$ ), but any organ of the body may be affected. Renal involvement constitutes only 2 to $3 \%$ 
of all cases. The rupture into the renal pelvis results in acute flank pain, then voiding of scolices, or daughter cysts (hydatiduria) with or without hematuria and urinary obstruction. The main treatment is surgery.

\section{Resat Ozaras, Ali Mert, Ensar Yekeler*, Aygul Dogan Celik, Fehmi TabaK and Recep Ozturk}

Infectious Diseases and Clinical Microbiology, Cerrahpasa Medical Faculty and *Radiology, Istanbul Medical Faculty, Istanbul University, Istanbul, Turkey

Received for publication August 15, 2003; Accepted for publication September 27, 2003

Reprint requests should be addressed to Dr. Resat OZARAS, Infectious Diseases and Clinical Microbiology, Cerrahpasa Medical Faculty, Istanbul University, TR-34303 Cerrahpasa, Istanbul, Turkey 